\title{
THE CHANGING FACE OF NEUROLOGICAL REHABILITATION
}

\author{
CARR JH, SHEPHERD RB \\ School of Physiotherapy, Faculty of Health Science, University of Sydney, Lidcombe, Australia \\ Correpondence to: Janet H Carr, School of Physiotherapy, Faculty of Health Science, University of Sydney, East St., \\ Lidcombe NSW 2141, Australia, e-mail: J.Carr@fhs.usyd.edu.au
}

Received: 07/02/2006 - Accepted: 15/02/2006

\begin{abstract}
Background: Neurological rehabilitation and the contribution of physical therapy have changed considerably over the past decades as scientific and technological developments have enabled greater understanding of brain reorganization and the mechanisms of motor control, motor performance, impairments and adaptations. Objective: This paper presents a historical perspective covering the last half-century. Discussion: Current scientific research, and the subsequent reevaluation of the functional effects of impairments following an upper motor neuron lesion, is leading to a changing focus in clinical interventions, with emphasis on optimizing motor performance through task-oriented exercise and training, strength and fitness training. Findings in both animal and human models suggest that, for rehabilitation to be effective in optimizing neural reorganization and functional recovery, increased emphasis needs to be placed on challenging, engaging and meaningful task training, to promote learning. The issues of the intensity of task training and extent of cardiovascular stress during physical activity are also discussed. Although there is much to become excited about in the findings from clinical research, clinical practice in neurorehabilitation continues to vary widely and depends largely on the preferred approach of the individual therapist and on the continuing dominance of therapeutic methods developed half a century ago. Physiotherapists need to embrace the responsibility of using evidence-based, or at least scientifically acceptable, methods of intervention and objective measurements of outcome.
\end{abstract}

Key words: neurorehabilitation, functional recovery, task-oriented exercise, training.

\section{RESUMO}

\section{Mudando a Face da Reabilitação Neurológica}

Introdução: A reabilitação neurológica e a contribuição da fisioterapia mudaram consideravelmente nas últimas décadas, uma vez que o desenvolvimento científico e tecnológico permitiu uma maior compreensão dos mecanismos de reorganização cerebral e dos mecanismos envolvidos no controle e desempenho motores, em suas dificuldades e adaptações. Objetivo: Este artigo apresenta uma perspectiva histórica da segunda metade do século passado. Discussão: Pesquisas científicas atuais e a subseqüente reavaliação do efeito funcional dos problemas que aparecem pela lesão do neurônio motor superior estão levando à mudança de foco das intervenções clínicas, com ênfase na otimização motora através de exercícios de tarefas orientadas, de ganho de força e de treino de desempenho físico. Achados em modelos animais e humanos sugerem que, para que a reabilitação seja eficiente em otimizar a reorganização neural e a recuperação funcional, uma ênfase maior deve ser colocada em tarefas úteis que sejam desafios interessantes com um treino que promove o aprendizado. As questões da intensidade do treino de tarefas e da extensão do estresse cardiovascular durante a atividade física também são discutidos. Embora exista muito que se aprender em achados de pesquisa clínica, a prática clínica da reabilitação continua ser altamente variada, dependendo largamente do método preferido pelo terapeuta individual, e com predomínio dos métodos terapêuticos desenvolvidos meio século atrás. Fisioterapeutas necessitam assumir a responsabilidade do uso de técnicas baseadas em evidências, ou pelo menos usar métodos de intervenção e medidas objetivas de resultados que sejam cientificamente aceitáveis.

Palavras-chave: reabilitação neurológica, recuperação funcional, exercícios de tarefas orientadas, treinamento. 


\section{INTRODUCTION}

\section{Historical Perspectives}

Understanding the history of physical therapy practice enables us to reflect on change and development in clinical practice and to feel more comfortable about the notion that clinical practice must respond and adapt as new scientific knowledge emerges. The history of neurological physical therapy exemplifies the process of change. Practitioners early in the $20^{\text {th }}$ century used forms of corrective exercise and muscle re-education, the latter involving exercises directed at individual muscles, with consideration of the roles of synergistic muscles. The knowledge that clinicians applied in their practice reflected an early focus on structural anatomy and principles of exercise as understood at the time. Many of those receiving physical therapy were individuals with muscle weakness and paralysis from poliomyelitis. This emphasis was to shift as the numbers of people acquiring poliomyelitis gradually declined with new preventive therapies and, following the second world war, an influx of young adults with acute brain injury helped drive the development of new therapies.

\section{Origins of the neurofacilitation approaches}

In the 1950s, a major conceptual shift in neurological physical therapy was evident as the neurophysiological or neurofacilitation approaches were developed. The focus changed from the muscle to non-muscle elements. Methods were directed primarily at the nervous system with movement facilitated by stimulation of the nervous system. Major influences were the work of the Bobaths ${ }^{1,2}$, in Bobath Therapy or Neurodevelopmental Therapy (NDT), and of Kabat, Knott and Voss ${ }^{3}$, whose methods of movement facilitation were referred to as Proprioceptive Neuromuscular Facilitation (PNF). Other therapists also developed their ideas for therapy around this time, including Rood, Ayres and Brunnstrom.

These approaches to therapy are often referred to as eponymous as they were named after their originators ${ }^{4}$. Although the originators had different and sometimes conflicting approaches, their methods reflected their interpretations of early neurophysiological writings with experimental paradigms including stimulus-response mechanisms, many of them based on animal models. Therapeutic methods focused on facilitating movement by afferent stimulation, specifically of muscle and joint proprioceptors and tactile receptors. Their methods were based on ideas of the restorative effects of encouraging developmental movement patterns, and emphasized postural stability and normal movement patterns. The Bobaths held the view that the normalizing of muscle tone by methods of inhibiting spasticity (abnormal postural tone) should take place before more normal movement could be facilitated. They held the view that movements requiring effort would increase spasticity and should therefore be avoided. Interestingly, these approaches paid little attention to developments in neuroscience including those related to the context-dependent nature of movement ${ }^{5}$.

\section{Developments in the 1980s}

The above therapeutic approaches, particularly those of Bobath and Knott and Voss, dominated the second half of the $20^{\text {th }}$ century and are still widely used. However, during this time there were newer developments, as physiotherapists and others who had access to the scientific literature sought ways of transferring new scientific findings to clinical practice. These developments took advantage of experimental work that focused on how humans acquire skill in movement or motor learning 6,7 , on muscle biology and muscle adaptability ${ }^{8,9}$, and on psychology ${ }^{10}$. These developments reflected to a large extent the increasing opportunity for physiotherapists to enroll in postgraduate courses, thereby developing research skills and engaging in intensive study of specific scientific fields. Not surprisingly, they saw the clinical implications.

The early attempts at developing therapy methods to improve functional movement were largely inductive (seeking a theoretical explanation for observed events), and this may have been partly due to the lack of a relevant scientific body of knowledge on human movement from which clinical implications could be more deductively derived. Over the last few decades, however, technological developments together with changes in the conceptualization of how the human nervous system might function to produce skilled movement, have been producing an increasing volume of movement-related research, in the fields of biomechanics and neuroscience in particular, that has obvious relevance to clinical practice. Experimental paradigms have shifted from a reductionist approach, in which the focus was, for example, on stretch reflex mechanisms using animal models, to an exploration of mechanisms of movement control in humans from the perspectives of performance as well as of physiological mechanisms. Technological developments in motion analysis and electromyography (EMG) have enabled studies of actions such as walking, standing up and reaching to pick up an object that demonstrate the kinematics and kinetics of each action, including the specific postural adjustments. New brain imaging methods are enabling an examination of organizational changes occurring within the brain itself and of the experiences that might drive them, particularly the effects of patterns of use and learning.

The increase in clinically relevant research findings related to movement therefore made possible the development of neurological rehabilitation by a more deductive process. Clinical implications were derived from a theoretical science base, and new clinical methods were developed and tested. As an example, for the action of sit-to-stand, there is now 
a rational biomechanical model that forms the basis for standardized guidelines for training this action ${ }^{11-14}$. This model has also provided methods for measuring performance and an increased focus on clinical research is enabling us to test the efficacy of interventions.

\section{Hybridization}

However, the process of change can be difficult for both teacher and practitioner and there is a temptation to combine newer methods with older methods that are still in use. This can occur even when there is no evidence that the older methods are effective. In the history of scientific endeavor there have always been attempts (usually unsuccessful) to integrate new methods with old at times of major change ${ }^{15}$. This mixing is called hybridization.

The move toward hybridization can be compelling, and "the case for reconciliation of competing paradigms is superficially attractive"15. Hybridization can seem attractive to a physiotherapist when there is a reluctance to let go of familiar therapeutic methods and move on. However, competing paradigms have philosophical and conceptual differences ${ }^{15}$, as they are based on different information regarding, for example, how the system is organized or the nature of impairments after a lesion.

\section{BRIDGING THE GAP BETWEEN SCIENCE AND CLINICAL PRACTICE}

\section{Re-evaluating the Functional Effects of Impairments}

The need for practice to move on by responding to new knowledge is well illustrated by examining research over the last few years that is changing the way in which we view impairments following a lesion of the upper motor neuron system. A re-evaluation of the relative contributions of muscle weakness and adaptive changes in muscles such as increased stiffness and spasticity is driving significant changes in clinical practice. The view that spasticity is the major impairment underlying movement dysfunction led to the development of methods based on the premise that spasticity had to be decreased or inhibited in order to facilitate more normal movement ${ }^{1,2}$. This view has been very influential over the past few decades. Muscle weakness has not been a primary focus in physical therapy until recently, as spasticity was considered the cause of weakness and disability. Congruent with this view, therapists have avoided exercise that required effort (as in strength training) since this effort was assumed to increase spasticity.

Contemporary research findings supporting the view that the major impairments interfering with functional performance following upper motor neuron lesions are paralysis, weakness (absent or reduced muscle force generation) and loss of dexterity (disordered motor control) ${ }^{16}$ are of major significance in planning interventions. So also is our increasing understanding that soft tissue adaptations occurring in response both to muscle weakness and to postlesion inactivity and disuse can impact negatively on the potential for regaining function. Soft tissue adaptations include increased muscle stiffness (stiffness is a mechanical response to load on a non-contracting muscle), and structural and functional reorganization of muscle and connective tissue ${ }^{17,18}$.

Muscle weakness arises from two sources, primarily from the lesion itself as a result of a decrease in descending inputs converging on the final motor neuron population and a resultant reduction in the number of motor units available for recruitment ${ }^{19}$. In addition, the neural lesion can result in a decreased firing rate of motor units and impaired motor unit synchronization ${ }^{20}$. These factors cause disorganization of voluntary motor output at the segmental level and may underlie the motor control problems exhibited by patients even when they are able to generate some muscle force ${ }^{14}$. Loss of the ability to generate power (force $\mathrm{X}$ velocity) may be a more significant cause of impaired motor performance than decreased force production ${ }^{21}$. The ability to generate large muscle forces is of little functional benefit if movement occurs too slowly to be effective ${ }^{5}$. Power output after stroke has been shown to be low in a number of studies ${ }^{21-23}$, and a low velocity of muscle contraction is evident clinically in the slowness of movement typical of people after stroke ${ }^{12}$.

Skeletal muscles adapt to the level of use imposed on them ${ }^{24}$, and secondary sources of weakness therefore arise as a consequence of lack of muscle activity and immobility ${ }^{25}$. Increasingly, evidence is provided of a relationship between muscle strength and function ${ }^{26-28}$.

The significance of spasticity (defined as velocitydependent stretch reflex hyperactivity ${ }^{29}$ ) for the regaining of motor function remains equivocal. There is little to support the view that reflex hyperactivity is a significant contributor to movement dysfunction after stroke. Some reports indicate stretch reflex hyperactivity can develop some time after the lesion, suggesting that it may be an adaptive response to nonfunctional, contracted stiff muscles ${ }^{30}$. In clinical practice, increased resistance to passive movement is typically referred to as spasticity although mechanical and functional changes to muscle are likely to be major contributors. Clinical tests such as the Ashworth Scale that are commonly used in clinical research are unable to distinguish the relative contributions of increased stiffness of muscles and reflex hyperactivity 31 .

\section{Optimizing Motor Performance}

Our own collaborative theoretical and investigative work has developed over the years, broadly based on research related to human movement, and updated as new developments emerge in science, and as evidence of the effects of intervention slowly began filtering into the literature from clinical studies. The principal research areas driving our work include motor control mechanisms, muscle biology, biomechanics, skill acquisition (motor learning) and exercise 
science $^{13,14,32}$. One point of interest is that the focus is strongly on the importation of theories and data from fields other than physical therapy, illustrating the nature of physical therapy as an applied clinical science.

Our work over the past few decades has focused on the patient as learner and on the need for task-oriented exercise and training, together with strength and fitness training, as the means of improving the patient's capacity to learn motor skills and optimize functional motor performance. An increasing number of investigations of this theoretical perspective have found positive effects in individuals with brain lesions. Improved functional performance suggests that learning has taken place ${ }^{27,33-44}$. In addition, training that is sufficiently intensive can increase muscle endurance and produce a cardiovascular training effect. Where strength has been particularly targeted, findings show increased strength and, in some cases, improved functional performance. Whether or not strength training results in improved function may, however, depend on the extent of muscle weakness. Interestingly, strength training does not result in increased resistance to passive movement (hypertonus) or reflex hyperactivity (spasticity).

It appears that exercise needs to be specific to the task being learned and the context, if performance of that task is to improve $\mathrm{i}^{45}$, since muscle strength and motor control are relative to the action being performed and its context. Skilled performance needs not only the generation of sufficient muscle force, but also the grading, sustaining and timing of force from many muscles in order to control body movement throughout the action. In particular, generation of muscle force needs to be fast enough to meet task demands.

The evidence so far suggests that physical therapy practice should emphasize the need to drive limb use. Training involves modifying the task and environment to ensure that the paretic limbs are actively involved. Training of walking, utilizing a treadmill (TT), is a promising method for retraining gait and increasing speed, endurance and cardiovascular fitness. Load on the musculoskeletal system can be increased or decreased by varying body weight support (BWS), and walking speed can be controlled. TT facilitates the cyclic gait pattern and can induce a shift toward temporal symmetry and increased paretic stance time ${ }^{46}$. TT, with or without BWS support, is a means of increasing the amount and intensity of practice. For dependent walkers, TT with BWS may be the only means of practicing walking in the early phase of recovery $^{47}$.

A systematic review of treadmill training with and without BWS after stroke found a trend toward TT, such that BWS was more effective at improving gait speed when speed was aggressively targeted ${ }^{39}$ than in other interventions, and significant increases in endurance were evident in several studies $^{48}$. When TT is part of an overall task-oriented training regimen, research findings suggest that such a program is superior at enhancing walking capacity post-acute stroke, compared with $\mathrm{NDT}^{49}$, and in chronic stroke compared with sham therapy ${ }^{36,40}$. However, a closer look at the evidence suggests that the key factor in these studies is the presence of varied and intensive task-oriented practice of locomotor activities. There is also evidence of transfer from TT to overground walking. In addition, training of overground walking includes walking over obstacles and in different environments, and with differing cognitive demands.

After a series of primate studies, Taub ${ }^{50}$ described a phenomenon called "learned non-use", which he proposed may underlie the difficulty some individuals have in using the affected upper limb, despite the presence of an apparently sufficient level of muscle activity. Constraint-induced movement therapy (CIMT) involves restraint of the nonparetic limb over an extended period with challenging taskoriented training of the paretic limb ${ }^{51,52}$. A recent systematic review $^{53}$ found growing evidence to support the use of CIMT, compared with alternative and/or no treatment (see recommended protocol ${ }^{14}$ ). Further evidence comes from reports of an association between improved motor performance, increased use of the limb and brain reorganization ${ }^{54}$. It is critical that effects of particular treatments on function include the effect on actual use of the limb in daily life (for example: Motor Activity Log or Actual Amount of Use Test ${ }^{51}$ ).

There is increasing interest in the potential of electrical stimulation (ES) or neuromuscular ES to reduce the development of secondary adaptive changes in muscles, to initiate activity in denervated or very weak muscles and to prevent stretching of rotator cuff muscles and the glenohumeral joint capsule. ES enables repetitive muscle exercise in those individuals who have little active movement in the acute stage. ES has had a long and varied history in rehabilitation following stroke. The findings in two comprehensive reviews ${ }^{55,56}$ suggest that the use of ES may reduce shoulder subluxation, at least in the short term, and may reduce shoulder pain. Combining afferent biofeedback from an EMG signal with ES in individuals who can partially activate paretic muscles but are unable to generate sufficient muscle contraction for functional purposes may prove to be an aid to task-oriented training. Both reviews point to the need for further research.

\section{Neural reorganization and functional recovery}

Insight into mechanisms mediating motor recovery after injury to the sensorimotor cortex is now beginning to emerge. Neurophysiological and neuroanatomical studies in animals, and neuroimaging and other non-invasive mapping studies in humans, are providing substantial evidence that the adult cerebral cortex is capable of significant functional reorganization (for example ${ }^{57,58}$ ). These studies have demonstrated plasticity in the functional topography and anatomy of intact cortical tissue adjacent to the injury and of more remote cortical areas. Of critical importance for 
rehabilitation is that experience, learning and active use of the affected limbs appear to modulate the adaptive reorganization that inevitably occurs after cortical injury. From current research, it seems likely that, for rehabilitation to be effective in optimizing neural reorganization and functional recovery, increased emphasis needs to be placed on challenging, engaging and meaningful task training to promote learning (for example $\mathrm{e}^{54,59,60}$ ). In addition, research findings indicate significant gains and enhanced structural plasticity when therapy is commenced early suggesting that delaying commencement of rehabilitation may reduce the efficacy of treatment $^{61}$.

\section{Motor learning}

As physiotherapists, we are becoming increasingly aware of patients as active participants in training rather than as passive recipients of therapy. The idea that motor learning research can provide a rich source of scientific information to guide clinical practice has been available to the profession for several decades.

Performance of an action that is effective in consistently achieving a specific goal with some economy of effort is said to be skilled. Motor learning itself cannot be directly observed. It is a set of complex internal processes that can only be inferred from a relatively consistent improvement in performance of an action, that is, a relatively stable change in motor behavior as a result of practice of that action ${ }^{62,63}$. To know whether or not performance has improved, the therapist measures the person's performance at the start of training, at various stages throughout rehabilitation and periodically after discharge to see whether or not performance gains have been maintained.

For several decades, scientists have investigated the process of acquiring skill, typically with healthy adults as they train to improve a specific skill and increasingly with people with motor disability. Gentile ${ }^{64}$ describes the stages of learning as first getting the idea of the movement, then developing the ability to adapt the movement pattern to environmental demands. In the initial stages the person learns to pay attention to the critical features of the action and is actively engaged in practice. Considering the patient as a learner involves setting up environments and methods of delivery that stimulate skill learning.

As part of the training process, the therapist may direct the patient's focus of attention away from an internal bodyoriented focus (the feet or upper body movement) to an external focus that is directly related to the goal (avoiding obstacles on the floor). For example, the learner's focus of attention can shift as muscle strength, motor control and skill increase. In walking it may shift from the feet to the surrounding environment; the star billing for sit-to-stand may change from initial foot placement backward and increasing the speed of forward rotation of the upper body, to the need to steady a glass of water while standing up. Some recent findings with healthy subjects have shown what a difference it can make to performance and skill development if the learner directs attention toward the effect of the movement (an external focus) instead of to the movement itself (an internal focus) $)^{65}$.

Skilled performance is characterized by the ability to perform complex movements, with the flexibility to vary movement to meet ongoing environmental demands with economy of effort. This applies as much to everyday actions such as walking and standing up from a seat, as it does to recreational, sporting or work-related actions.

Skill is task-specific. Although such actions as level walking and stair walking may share similar biomechanical characteristics, the demands placed on the individual by each action are different. The individual learns to reshape and adapt the basic movement pattern according to different contexts. Crossing the street at pedestrian lights may require an increase in walking speed, while negotiating a step or obstacles in the house requires other changes in the walking pattern.

Improvement in a particular action therefore requires practice of that action; that is, the learner practices to become effective and efficient in achieving a specific goal. For some individuals, speeding up the action and improving power generation may be major performance goals. However, for those whose muscle strength and motor control is below a certain threshold, such practice may not be possible. Exercises to increase strength and control may be necessary, together with practice of the action under modified conditions, for example, standing up from a higher seat which requires less muscle force generation. Many repetitions of an action are required to increase strength and for the patient to develop an optimal way of performing the action ${ }^{66}$. Physical therapy has neglected the repetitive element of both strength training and skill training that form essential prerequisites in motor rehabilitation.

In training functional tasks, the therapist sets the goals in consultation with the individual and based on evaluation of the person's capabilities. As the "coach”, the therapist may point out how a movement is organized, based on knowledge of critical biomechanical characteristics; provide demonstration, verbal instructions and feedback; direct the person's visual attention; or highlight regulatory cues in the environment (for example, the height of an obstacle). However, it is the patient who must learn to organize movement that matches the environment in order to achieve these goals, and this is accomplished by physical (and mental) practice.

The environment needs to be organized to be functionally relevant by providing meaningful objects of different sizes, weight and graspability, which allow for different tasks to be trained. Goals are concrete rather than abstract: "Reach out and take the glass from the table" rather than "Raise your arm". "Reach sideways to pick up the glass from the floor" rather than "Shift your weight over to the left". Recent research has illustrated well the different outcomes when post-stroke 
individuals work with concrete goals linked to real objects rather than with more abstract goals ${ }^{67,68}$. Wu et al ${ }^{68}$ examined a task in which subjects used one hand to scoop coins from a table into the other hand. Able-bodied and stroke subjects took part, sometimes with coins, sometimes mimicking the movement without coins. Both groups of subjects demonstrated faster movements, with smoother and straighter reaches, which are characteristics of well-learned coordinated movement, when they scooped the coins rather than when they mimicked the action.

\section{Rehabilitation environment}

If brain reorganization and functional recovery from brain lesions is dependent on use and activity, then the rehabilitation environment is likely to play an important role in patient outcomes. The rehabilitation environment is made up of the physical or built environment (the physical setting), the methods used to deliver rehabilitation (type of intervention, intensity, dosage) and the staff (their knowledge, skill, attitudes, and their ability to teach).

Evidence from animal experiments suggests that the nature of the environment and its physical structure, together with the opportunities it offers for social interaction and physical activity, can influence outcome after a lesion. In animal research, the aspects of the enriched environment that appear to be critical as enhancers of behavior are social stimulation, interaction with objects that enable physical activity ${ }^{69}$, and an increased level of arousal ${ }^{70}$.

Observational studies of rehabilitation settings provide insights into how patients spend their days, suggesting that the environment may not be sufficiently geared to facilitating physical and mental activity or social interaction, and that it may not function as a learning environment ${ }^{71}$. Other studies suggest that a large percentage of the patient's day is spent in passive pursuits rather than in physical activity. The issue of how much time is spent on physical activity, including practice of motor tasks, and how this time is organized, is therefore a critical one for rehabilitation.

\section{Delivery of physical therapy}

Focusing on intensive task-oriented training has required some changes in physical therapy practice, not only in the methods used but also in delivery. Physiotherapists are exploring different ways of organizing delivery to enable the patient to be an active learner. They are examining, for example, the effects of an interactive relationship between patient and therapist, the effects of working in a small group during circuit training, and the effects of sessions where patients work in partnership with each other ${ }^{72}$.

In an attempt to increase the time spent practicing, several investigators have reported the development of technology to provide computer-aided training, for example, robot-mediated therapy (RMT) $)^{73-75}$. The focus has been on movements of the upper extremity that are challenging, engaging and repetitious. Significantly more improvement in upper limb function has been reported compared with NDT/ Bobath therapy of equal intensity and duration ${ }^{74}$. In addition, the rate of recovery when treatment was delivered with RMT was found to be greater in relation to either no treatment or treatment with sling suspension in a single case study ${ }^{75}$. The generalizability of RMT and its role in motor learning are yet to be tested.

\section{Intensity of skill practice and exercise}

Two aspects of therapy for neural lesions that have received little attention until recently are the intensity of taskoriented training and the extent of cardiovascular stress induced during physical activity. Endurance training, like poststroke strength training, has long been neglected because of the dogma related to spasticity. It is not only important for patients to practice in order to regain skill in performing actions, but it is also critical that they regain sufficient strength, endurance and fitness to be able to carry out these actions. It is well documented that stroke patients have low physical endurance when discharged from rehabilitation.

Deconditioning can occur within the first six weeks after stroke. In a study that measured exercise capacity in the early post-stroke period, patients performed incremental maximal effort tests on a semi-recumbent cycle ergometer ${ }^{76}$. Deconditioning may be a consequence of the relatively static nature of typical rehabilitation programs and indicates that intensity of training needs to be addressed specifically and early after an acute brain lesion, in an effort to decrease the deconditioning effects.

Recently, MacKay and Makrides ${ }^{77}$ investigated the aerobic component of physical therapy and occupational therapy for stroke patients by monitoring heart rate (using heart rate monitors) and therapeutic activities biweekly over a 14-week period. The major finding was that the therapy sessions involved low intensity exercise and activity that did not provide adequate metabolic stress to induce a training effect. Although progressively higher exercise intensities might be expected over time as functional status improves, any increase in $\mathrm{HR}_{\text {mean }}$ and $\mathrm{HR}_{\text {peak }}$ did not reach statistical significance.

The detrimental effect of low exercise capacity and muscle endurance on functional mobility and resistance to fatigue can be compounded by the high metabolic demand of adaptive movements. Stroke patients discharged from rehabilitation showing improvements in gait are not necessarily functional walkers but are often unable to maintain their most efficient walking speed comfortably, thus indicating that the high energy cost of walking and poor endurance further compromise functional performance ${ }^{78,79}$.

The calculation of walking speed over $10 \mathrm{~m}$, a commonly used clinical measure of gait, may overestimate locomotor capacity after stroke. Healthy subjects can walk in excess of their comfortable speed for at least six minutes. Stroke 
subjects, however, may not be able to maintain their comfortable speed over that time ${ }^{80}$. This would prevent them from becoming competent community walkers, and may lead to increasing handicap. These results emphasize the need to train endurance and to measure endurance using a test such as the 6-minute walk ${ }^{81}$.

Improvements in aerobic capacity in chronic stroke have been demonstrated with appropriate training such as bicycle training $^{82}$, graded treadmill walking ${ }^{83}$ and combined aerobic and strengthening exercises ${ }^{42}$. As might be expected, the effects are exercise-specific. Generalization to everyday life, however, is also reflected in the improvements noted in general health and wellbeing. Teixeira-Salmela et $\mathrm{al}^{42}$ assessed their subjects' general level of physical activity in the Human Activity Profile, a survey of 94 activities that are rated according to their required metabolic equivalents. The results indicated that subjects were able to do more household chores and to increase their participation in recreational activities more than before the training program.

\section{CONCLUDING COMMENTS}

The regaining of skill in critical tasks requires specific training, with intensive practice of actions in the appropriate contexts. In addition, the individual must be fit enough to perform the tasks of daily life, including taking part in social and recreational activities. Participation in regular exercise and training appears to have significant effects on reducing disability and improving quality of life in older adults and in individuals with disability. The benefits of task-oriented skill training and strength training are also being reported in studies of children with cerebral palsy ${ }^{84,85}$. Although in these children the primary deficits are neural, adaptive changes in musculoskeletal and cardiorespiratory systems also impose severe limitations on the gaining of functional motor performance ${ }^{86,87}$. Many of these changes are preventable or reversible ${ }^{88}$.

Post-discharge services for individuals with chronic disability are, however, poor or non-existent and there are reports of high levels of patient dissatisfaction ${ }^{89}$ and loss of rehabilitation gains ${ }^{90}$. The provision of facilities such as strength and fitness centers directed at all age groups and disability levels requires collaboration between public health and community services. Physiotherapists can play a significant role in this collaborative process.

Entry-level physical therapy curricula also have to respond to evidence of the significance of task-oriented training and strength, endurance and fitness training for individuals with acute or chronic disability. Core knowledge should include biomechanics, exercise science and motor learning. The skills required for training individuals with disability, and how to adapt training and exercise to the patient's level of performance, should also form a large part of the education of physical therapy students as well as part of skills upgrading in continuing professional education.

It is a matter of increasing concern that clinical interventions in neurorehabilitation continue to vary widely and depend largely on the preferred approach of the individual therapist $^{5,91}$, and on the continuing dominance of therapeutic methods developed half a century ago. Lack of both a rational theoretical basis for a treatment method and of any evidence of its effectiveness may be no barrier to its continued use.

To make the change to practice based on evidence and on current theoretical relevance is a large undertaking but already taking place around the world. A start can be made in clinical practice by following prescribed guidelines that are based on available evidence. These are available in texts and in other work cited here. Each physiotherapist needs to accept the responsibility of using evidence-based (or at least scientifically acceptable) methods of intervention and ongoing outcome measurements, including quality-of-life profiles. Patients have the right to be part of an up-to-date neurorehabilitation environment.

\section{REFERENCES}

1. Bobath B. Abnormal reflex activity caused by brain lesions. Oxford: Heinemann; 1965.

2. Bobath B. Adult hemiplegia: Evaluation and treatment. $3^{\text {rd }}$ ed. Oxford: Butterworth Heinemann 1990.

3. Knott M, Kabat H. Proprioceptive facilitation therapy for paralysis. Physiotherapy 1954; 40: 171-76.

4. Gordon J. Assumptions underlying physical therapy interventions: theoretical and historical perspectives. In: Carr JH, Shepherd RB, editors. Movement science foundations for physical therapy in Rehabilitation. $2^{\text {nd }}$ ed. Gaithersburg: Aspen ; 2000. p.1-31.

5. Newham DJ. Muscle performance after stroke. In: Refshauge K et al., editors. Science-based Rehabilitation. Oxford: Butterworth Heinemann; 2005. p. 67-85.

6. Carr JH, Shepherd RB. Physiotherapy in disorders of the brain. Butterworth Heinemann: Oxford; 1980. p. 71-93.

7. Carr JH, Shepherd RB. A motor relearning programme for stroke. $2^{\text {nd }}$ edition. Oxford; Butterworth Heinemann.1987.

8. Rose SJ, Rothstein JM. Muscle mutability Part 1. General concepts and adaptations to altered patterns of use. Physical Therapy 1982; 62: 1773-85.

9. Gossman MR, Sahrmann SA, Rose SJ. Review of length-associated changes in muscle. Physical Therapy 1982; 62: 17991808.

10. Anderson M, Lough S. A psychological framework for neurorehabilitation. Physiotherapy Practice 1986; 2: 74-82.

11. Shepherd RB, Koh HP. Some biomechanical consequences of varying foot placement in sit-to-stand in young women. Scandinavian Journal Rehabilitation Medicine 1996; 28: 79-88. 
12. Carr JH, Ow JEG, Shepherd RB. Some biomechanical characteristics of standing up at three different speeds: implications for functional training. Physiotherapy Theory Practice 2002; 18: 47-53.

13. Carr JH, Shepherd RB. Neurological rehabilitation optimizing motor performance. Oxford: Butterworth Heinemann; 1998.

14. Carr JH, Shepherd RB. Stroke rehabilitation: Guidelines for exercise and training. Oxford: Butterworth Heinemann; 2003.

15. Abernethy B, Sparrow WA. The rise and fall of dominant paradigms in motor behaviour research. In: Summers JJ, editor. Approaches to the study of motor control and learning. North Holland: Elsevier; 1992. p. 3-45.

16. Landau WM. Spasticity: what is it? What is it not? In: Feldman RG, Young RR, Koella WP, editors. Spasticity: disorder of motor control. Chicago: Year Book Medical; 1980. p17-24.

17. Sinkjaer T, Magnussen I. Passive, intrinsic and reflex-mediated stiffness in the ankle extensors of hemiparetic patients. Brain 1994; 117: 355-63.

18. Svantesson U, Takahashi H, Carlsson U et al. Muscle and tendon stiffness in patients with upper motor neuron lesion following a stroke. European Journal of Applied Physiology and Occupational Physiology 2000; 82: 275-79.

19. McComas AJ, Sica REP, Upton et al. Functional changes in motoneurones of hemiparetic patients. Journal of Neurology, Neurosurgery and Psychiatry 1973; 36: 183-93.

20. Gemperline JJ, Allen S, Walk D et al. Characteristics of motor unit discharge in subjects with hemiparesis. Muscle and Nerve 1995; 18: 1101-114.

21. Olney SJ, Richards C. Hemiparetic gait following stroke. Part 1: characteristics. Gait and Posture 1996: 4; 136-48.

22. Kautz SA, Brown DA. Relationships between timing of muscle excitation and impaired motor performance during cyclic lower extremity movement in post-stroke. Brain 1998; 121: 515-26.

23. Hsiao SF, Newham DJ. Bilateral deficits of voluntary thigh muscle contraction after recent stroke. In: Gantchev N, editor. From basic motor control to functional recovery. Sofia: Academic Publishing; 2001.

24. Lieber RL. Comparison between animal and human studies of skeletal muscle adaptation to chronic stimulation. Clinical Orthopaedic Related Research 1988; 233: 19-24.

25. Farmer SF, Swash M, Ingram DA et al. Changes to motor unit synchronisation following central nervous lesions in man. Journal of Physiology 1993; 463: 83-105.

26. Ng S, Shepherd RB. Weakness in patients with stroke: implications for strength training in neurorehabilitation. Physical Therapy Reviews 2000; 5: 227-38.

27. Teixeira-Salmela LF, Nadeau S, McBride I et al. Effects of muscle strengthening and physical conditioning training on temporal, kinematic and kinetic variables during gait in chronic stroke survivors. Journal of Rehabilitation Medicine 2001; 33: 53-60.

28. Chae J, Yang G, Park BK. Delay in initiation and termination of muscle contraction, motor impairment, and physical disability in upper limb paresis. Muscle and Nerve 2002; 25: 568-75.

29. Lance JM. Symposium synopsis. In: Feldman RG, Young RR, editors. Spasticity: Disorder of Motor Control. Chicago: Year Book Medical Pubs; 1980. p.485-494.
30. Gracies J-M, Wilson L, Gandevia SC, et al. Stretched position of spastic muscles aggravates their co-contraction in hemiplegic patients. Annals of Neurology 1997; 42: 438-39.

31. Katz RT, Rovai GP, Brait C. Objective quantitation of spastic hypertonus; correlation with clinical findings. Archives of Physical Medicine and Rehabilitation 1992; 73: 339-47.

32. Carr JH, Shepherd RB. A motor learning model for rehabilitation. In: Carr JH, Shepherd RB, editors. Movement Science Foundations for Physical Therapy in Rehabilitation. Rockville, MD: Aspen Publishers; 2000. p.33-110.

33. Brown DA, Kautz SA. Increased workload enhances force output during pedalling exercise in persons with poststroke hemiplegia. Stroke 1998; 29: 598-606.

34. Butefisch C, Hummelsheim H, Mauritz K-H. Repetitive training of isolated movements improves the outcome of motor rehabilitation of the centrally paretic hand. Journal Neurological Science 1995; 130: 59-68.

35. Dean CM, Shepherd RB. Task-related training improves performance of seated reaching tasks after stroke: a randomized controlled trial. Stroke 1997; 28: 722-28.

36. Dean CM, Richards CL, Malouin F. Task-related training improves performance of locomotor tasks in chronic stroke. A randomized controlled pilot study. Archives of Physical Medicine and Rehabilitation 2000; 81: 409-17.

37. Duncan P, Studenski S, Richards L, et al. Randomized clinical trial of therapeutic exercise in subacute stroke. Stroke 2003; 34: 2173-80.

38. Eng JJ, Chu KS, Kim M, et al. A community-based group exercise program for persons with chronic stroke. Medicine and Science in Sports and Exercise 2003; 35: 1271-1278.

39. Pohl M, Mehrholz J, Ritschel C, et al. Speed-dependent treadmill training in ambulatory hemiparetic stroke patients. Stroke 2002; 33: 553-58.

40. Salbach NM, Mayo NE, Wood-Dauphinee S. A task-oriented intervention enhances walking distance and speed in the first year post stroke: a randomized controlled trial. Clinical Rehabilitation 2004: 18; 509-18.

41. Sharp SA, Brouwer BJ. Isokinetic strength training of the hemiparetic knee: effects on function and spasticity. Archives of Physical Medicine and Rehabilitation 1997; 78: 1231-36.

42. Teixeira-Salmela LF, Olney SJ, Nadeau S, et al. Muscle strengthening and physical conditioning to reduce impairment and disability in chronic stroke survivors. Archives of Physical Medicine and Rehabilitation 1999; 80: 1211-18.

43. Visintin M, Barbeau H, Korner-Bitensky N, et al. A new approach to retrain gait in stroke patients through body weight support and treadmill stimulation. Stroke 1998; 29: 1122-28.

44. Weiss A, Suzuki T, Bean J, et al. High intensity strength training improves strength and functional performance after stroke. American Journal of Physical Medicine and Rehabilitation 2000; 79: 369-76.

45. Rutherford OM. Muscular coordination and strength training: implications for injury rehabilitation. Sports Medicine 1988; 5 : 196-202. 
46. Harris-Love ML, Forrester LW, Macko RF, et al. Hemiparetic gait parameters in overground versus treadmill walking. Neurorehabilitation and Neural Repair 2001; 15: 105-12.

47. Barbeau H, Visintin M. Optimal outcomes obtained with bodyweight support combined with treadmill training in stroke patients. Archive of Physical Medicine and Rehabilitation 2003; 84: 1458-65.

48. Moseley AM, Stark A, Pollock A. Treadmill training and body weight support for walking after stroke. The Cochrane Library 2005;4: 1-68.

49. Richards CL, Malouin F, Wood-Dauphinee S. Task-specific physical therapy for optimization of gait recovery in acute stroke patients. Archives of Physical Medicine and Rehabilitation 1993; 74: 612-20.

50. Taub E. Somatosensory deafferentation research with monkey: implications for rehabilitation medicine. In: Ince LP, editor. Behavioral Psychology in Rehabilitation Medicine: Clinical Applications. New York: Williams \& Wilkins; 1980. p.371-401.

51. Taub E, Miller NE,Novak TA, et al. A technique to improving chronic motor deficit after stroke. Archives of Physical Medicine and Rehabilitation 1993; 74: 347-54.

52. Taub E, Wolf SL. Constraint induced movement techniques to facilitate upper extremity use in stroke patients. Topics in Stroke Rehabilitation 1997; 3: 38-61.

53. Hakkennes S, Keating JL. Constraint-induced movement therapy following stroke: a systematic review of randomised controlled trials. Australian Journal of Physiotherapy 2005; 51: 221-31.

54. Liepert J, Uhde I, Graf S, et al. Motor cortex plasticity during forced-use therapy in stroke patients: a preliminary study. Journal of Neurology 2001; 248: 315-21.

55. Chae J, Yu D. A critical review of neuromuscular electrical stimulation for treatment of motor dysfunction in hemiplegia. Assistive Technology 2000; 12: 33-49.

56. Price CIM, Pandyan AD. Electrical stimulation for preventing and treating post-stroke shoulder pain: a systematic review. Clinical Rehabilitation 2001: 15; 5-1957.

57. Barbro J. Brain plasticity and stroke rehabilitation: The Willis lecture. Stroke 2000: 31; 223-30.

58. Nudo RJ, Plautz EJ, Frost SB. Role of adaptive plasticity in recovery of function after damage to motor cortex. Muscle and Nerve 2001; 8: 1000-19.

59. Nudo RJ, Friel KM. Cortical plasticity after stroke: implications for rehabilitation. Reviews of Neurology 1999; 9: 713-17.

60. Plautz EJ, Milliken GW, Nudo RJ. Effects of repetitive motor training on movement representation in adult squirrel monkeys: role of use versus learning. Neurobiology of Learning and Memory 2000; 74: 27-5561.

61. Biernaskie J, Chernenko G, Corbett D. Efficacy of rehabilitative experience declines with time after focal ischemic brain injury. Neurobiology of Disease 2004; 24: 1245-1254.

62. Schmidt RA. Motor and action perspectives on motor behavior. In: Meijer OG, K Roth, editors. Complex Motor Behavior: The Motor-action Controversy. Amsterdam: Elsevier; 1988. p. 3-44.

63. Magill RA. Motor learning concepts and applications. $6^{\text {th }}$ ed. New York: McGraw-Hill 2001.
64. Gentile AM. Skill acquisition: action, movement, and neuromotor processes. In: Carr JH, Shepherd RB, editors. Movement science foundations for physical therapy in Rehabilitation. $2^{\text {nd }}$ ed. Gaithersburg: Aspen, MD; 2000. p.111-187.

65. Wulf G, Hof M, Prinz W. Instruction for motor learning: differential effects of internal vs external focus of attention. Journal of Motor Behavior 1998; 30: 169-179

66. Latash LP, Latash ML. A new book by NA Bernstein: 'On Dexterity and its Development'. Journal Motor Behavior 1994; 26: 56-62.

67. Van Vliet P, Kerwin DG, Sheridan M, et al. The influence of goals on the kinematics of reaching following stroke. Neurology Repair 1995; 19: 11-16.

68. Wu C, Trombly CA, Lin K, et al. A kinematic study of contextual effects on reaching performance in persons with and without stroke: influences of object availability. Archives of Physical Medicine and Rehabilitation 2000; 81: 95-101.

69. Bennett EL. Cerebral effects of differential experience and training. In: Rosenzweig MR, Bennett EL, editors. Neural mechanisms of learning and memory. Cambridge MA: MIT Press; 1976. p. 297-287.

70. Walsh RN, Cummins RA Mechanisms mediating the production of environmentally induced brain changes. Psychology Bulletin 1975; 82: 986-1000.

71. Ada L, Mackey F, Heard R, et al. Stroke rehabilitation: does the therapy area provide a physical challenge? Australian Journal of Physiotherapy 1999; 45: 33-8.

72. McNevin NH, Wulf G, Carlson C. Effects of attentional focus, self-control, and dyad training on motor learning: implications for physical therapy. Physical Therapy 2000; 80: 373-85.

73. Volpe BT, Krebs HI, Hogan N, et al. A novel approach to stroke rehabilitation: Robot-aided sensorimotor stimulation. Neurology 2000; 54: 1938-44.

74. Lum PS, Burgar CG, Shor PC, et al. Robot-assisted movement training compared with conventional therapy techniques for the rehabilitation of upper-limb motor function after stroke, Archives of Physical Medicine and Rehabilitation 2002; 83: 95259.

75. Coote S, Stokes EK. Effect of robot-mediated therapy on upper extremity dysfunction post-stroke a single case study. Physiotherapy 2005; 91: 250-56.

76. Kelly J, Kilbreath SL, Davis GM, et al. Cardiorespiratory fitness and walking ability in acute stroke patients. Archives of Physical Medicine and Rehabilitation 2003; 84: 1780-85.

77. MacKay-Lyons MJ, Makrides L. Cardiovascular stress during a contemporary stroke rehabilitation program: is the intensity adequate to induce a training effect? Archives of Physical Medicine and Rehabilitation 2002; 83: 1378-83.

78. Olney SJ, Monga TN, Costigan PA. Mechanical energy of walking of stroke patients. Archives of Physical Medicine and Rehabilitation 1986; 67: 92-8.

79. Wade DT, Hewer RL. Functional abilities after stroke: measurement, natural history and prognosis. Journal of Neurology, Neurosurgery, and Psychiatry 1987; 50: 177-82 
80. Dean CM, Richards CL, Malouin F. Walking speed over 10 metres overestimates locomotor capacity after stroke. Clinical Rehabilitation 2001; 15: 415-21.

81. Guyatt GH, Sullivan MJ, Thompson PJ, et al. The 6-minute walk: a new measure of exercise capacity in patients with chronic heart failure. Canadian Medical Journal 1985; 132: 919-23.

82. Potempa K, Lopez M, Braun LT, et al. Physiological outcomes of aerobic exercise training in hemiparetic stroke patients. Stroke 1995; 26: 101-5.

83. Macko RF, De Souza CA, Tretter LD, et al. Treadmill aerobic exercise training reduces the energy and cardiovascular demands of hemiparetic gait in chronic stroke patients. Stroke 1997; 28: 326-30.

84. Damiano DI, Vaughan CL, Abel MF. Muscle response to heavy resistance exercise in children with spastic cerebral palsy. Developmental Medicine and Child Neurology 1995; 37: 731-39.

85. Blundell SW, Shepherd RB, Dean CM, et al. Functional strength training in cerebral palsy: a pilot study of a group circuit training class for children aged 4-8 years. Clinical Rehabilitation 2003; 17: 48-57.
86. Booth CM, Cortina-Borja MJ, Theologis TN. Collagen accumulation in muscles of children with cerebral palsy and correlation with severity of spasticity. Developmental Medicine and Child Neurology 2001; 43: 314-20.

87. Rimmer JH, Damiano DL. Maintaining or improving fitness in children with disabilities. In Topics in Pediatrics. Alexandria: American Physical Therapy Association; 2001. p.1-16.

88. Damiano DI. Strength, endurance, and fitness in cerebral palsy. Developmental Medicine and Child Neurology 2003; 45: Suppl 94: 8-10.

89. Tyson S, Turner G. Discharge and follow-up for people with stroke: what happens and why. Clinical Rehabilitation 2000; 14: 381-92.

90. Paolucci S, Grasso MG, Antonucci G, et al. Mobility status after inpatient stroke rehabilitation: 1 year follow-up and prognosis factors. Archives of Physical Medicine and Rehabilitation 2001; 82: 2-8.

91. Woldag H, Hummelsheim H. Evidence-based physiotherapeutic concepts for improving arm and hand function in stroke patients: a review. Journal of Neurology 2002; 249: 518-28. 